International Journal of Engineering \& Technology, $7(1.5)(2018)$ 191-195
International Journal of Engineering \& Technology
SPC
Website: www.sciencepubco.com/index.php/IJET
Research paper

\title{
An identity encryption cloud scheme based on SMTP using advanced blow fish algorithm
}

\author{
R. Vasantha ${ }^{1 *}$, R. Satya Prasad ${ }^{2}$ \\ ${ }^{1}$ Research Scholar, Department of CSE, Acharya Nagarjuna University, Guntur, India \\ ${ }^{2}$ Associate Professor, Department of CSE, Acharya Nagarjuna University, Guntur, India \\ *Corresponding author E-mail: vassurudramalla@gmail.com
}

\begin{abstract}
Essential strategies vicinity unit acquainted with send the lion's share structures to collect the desired info. thanks to the imperfectness of truely the best data coding and additionally the utilization of preferred coding calculation, that wasn't accelerated in standard approaches for the time period procedure, a consolidated coding calculation is planned. This planned calculation gives new stride to stay removed from weaknesses. we will be inclined to apply a few standard algorithms to code AN data as takes as soon as. At to start with, we will be inclined to create new calculation maintaining in mind the tip purpose to provide security issue and time imperative of operation then we have a tendency to be a part of AES utilising multiplexing of keys, development in DES key size and blowfish calculation, at that time we have a propensity to code info using the deliberate calculation. this could improve the protection and muddles the coding. throughout this paper we provide each the coding and unscrambling that backings incessantly application and calculation incorporates a helpful esteem and loss of life penalty this calculation crosswise over cloud advances in encryption and decryption info over SMTP based usually utility.
\end{abstract}

Keywords: Hybrid coding, Advance coding commonplace (AES), encoding commonplace (DES), Blowfish, Key length, Time quality, house quality.

\section{Introduction}

Encryption can be a way for ever-changing over undeniable content material to work content material. by using and big part of secured facts's location unit changed utilizing internet edges these might be effects recovered by spies inside the cluster framework. coding is largely utilised in saving cash, accounting, kingdom and national corporation, military and geologic areas. typically we've got got numerous coding algorithms that encode records, each coding algorithmic rule has its own specific kind of developing with undeniable content to work content material. the primary issue lately faced via the gadget engineers is protection, time taken to finish, danger of encryption the know-how. the basic notion of increasing key length can decorate the protection. but the tactic of enforcing in unmarried algorithmic rule will have the identical protection issue. to hold up a strategic distance from this we will be inclined to endorse combination calculation, which is able to utilize 3 or 4 coding methods to provide another key with large safety.

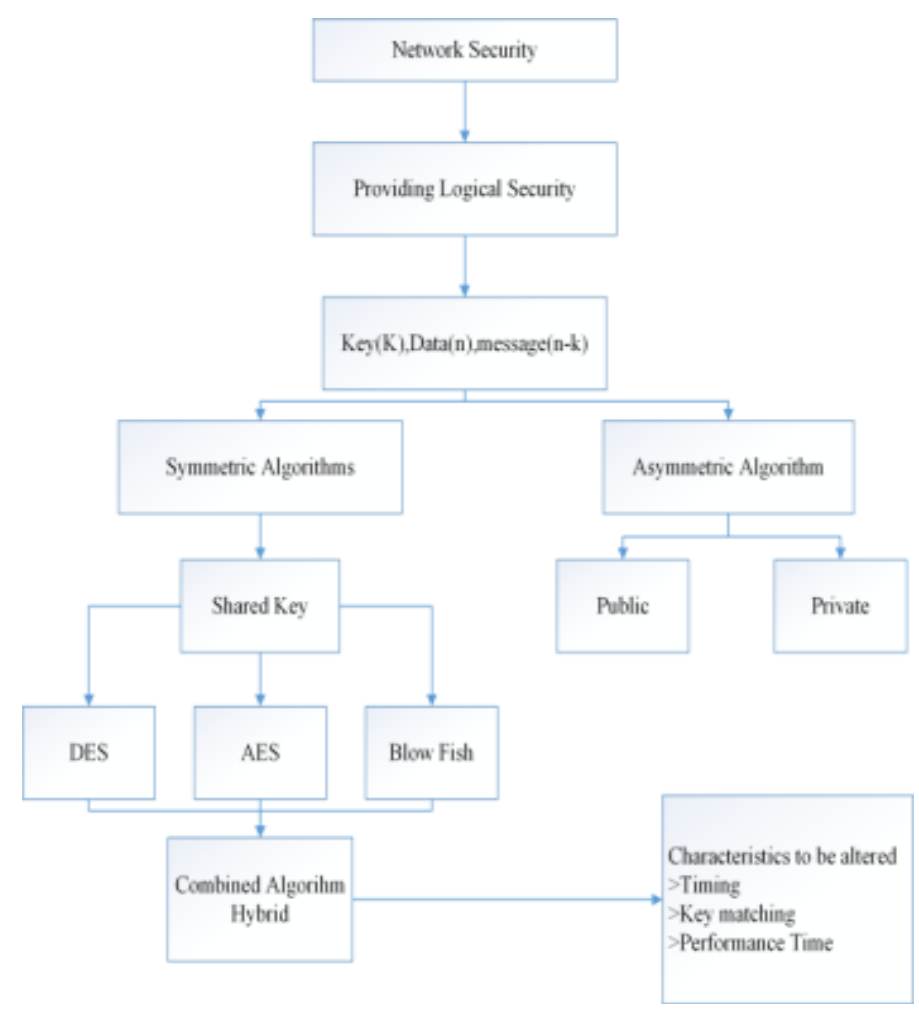

Fig. 1: Overview of Hybrid cryptography using symmetric encrption algorithms

\section{Literature Survey}


The DES set of rules is largely a monoalphabetic substitution cipher the use of a $64 \square$ bit person. At irrespective of cause a comparable 64-bit plaintext sq. is going inside the forepart, a comparable sixty four-bit parent content close returns out the end. A decoder will abuse this belongings to help ruin DES.to use DES at some stage in a form of utility four "modes of operation" are mentioned (FIPS saloon seventy four, eighty one). these 4 modes place unit predicted to cover for all intents and capabilities all the manageable use of cryptography that DES can be utilised. The modes place unit represented as takes when and made public in table one. these equal modes is connected for any centrosymmetric piece figure.

Table 1: DES Modes of Operation

\begin{tabular}{|c|c|c|}
\hline Mode & Description & Typical Application \\
\hline $\begin{array}{l}\text { Electronic Code } \\
\text { Book } \\
(\mathrm{ECB})\end{array}$ & Each block of 64 plaintext bits is encoded independently using the same key. & $\begin{array}{l}\text { Secure transmission of single values (e.g. } \\
\text { an encryption key) }\end{array}$ \\
\hline $\begin{array}{l}\text { Cipher Block } \\
\text { Chaining } \\
\text { (CBC) }\end{array}$ & $\begin{array}{l}\text { The input to the encryption algorithm is the XOR of the next } 64 \text { bits of plaintext and the } \\
\text { preceding } 64 \text { bits of ciphertext. }\end{array}$ & $\begin{array}{l}\text { General-purpose } \\
\text { transmission } \\
\text { Authentication }\end{array}$ \\
\hline $\begin{array}{l}\text { Cipher } \\
\text { Feedback } \\
(\text { CFB })\end{array}$ & $\begin{array}{l}\text { Input is processed } \mathrm{J} \text { bits at a time. Preceding ciphertext is used as input to the encryption } \\
\text { algorithm to produce pseudo-random output, which is XORed with plaintext to produce } \\
\text { next unit of ciphertext. }\end{array}$ & $\begin{array}{l}\text { General-purpose } \\
\text { transmission } \\
\text { Authentication }\end{array}$ \\
\hline $\begin{array}{l}\text { Output } \\
\text { Feedback } \\
\text { (OFB) }\end{array}$ & $\begin{array}{l}\text { Similar to CFB, except that the input to the encryption algorithm is the preceding DES } \\
\text { output. }\end{array}$ & $\begin{array}{l}\text { Stream-oriented transmission over noisy } \\
\text { channel (e.g. satellite communication) }\end{array}$ \\
\hline
\end{tabular}

\subsection{Materials and methods}

\section{Triple DES}

Given the ability vulnerabilities of DES to a savage electricity assault, there was significant enthusiasm for locating an option. One approach is to outline a very new calculation. Illustrations are international facts Encryption set of rules (idea), advanced
Encryption fashionable (AES), Blowfish, RC5, cast (developed by using Carlisle Adams and Stafford Tavares in 1997) and RC2 another option, which might protect the modern hobby in programming and hardware, is to utilize severa encryptions with DES and specific keys.the very best form of numerous encryption has two phases and keys as appeared in figure under. Given Plaintext $\mathrm{P}$ and two encryption keys $\mathrm{K} 1$ and $\mathrm{K} 2$, figure content $\mathrm{C}$ is produced as:

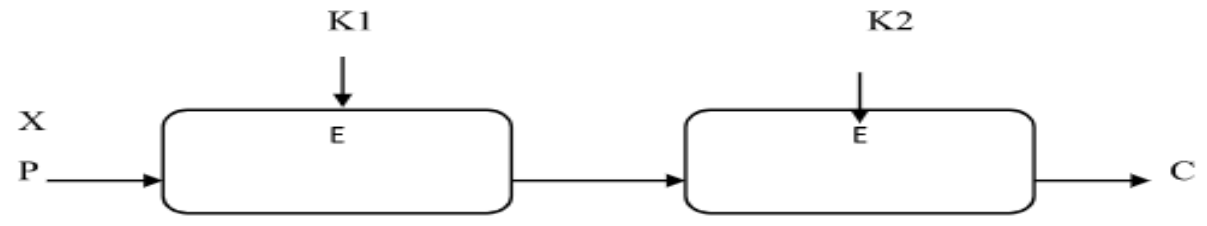

\section{Encryption}
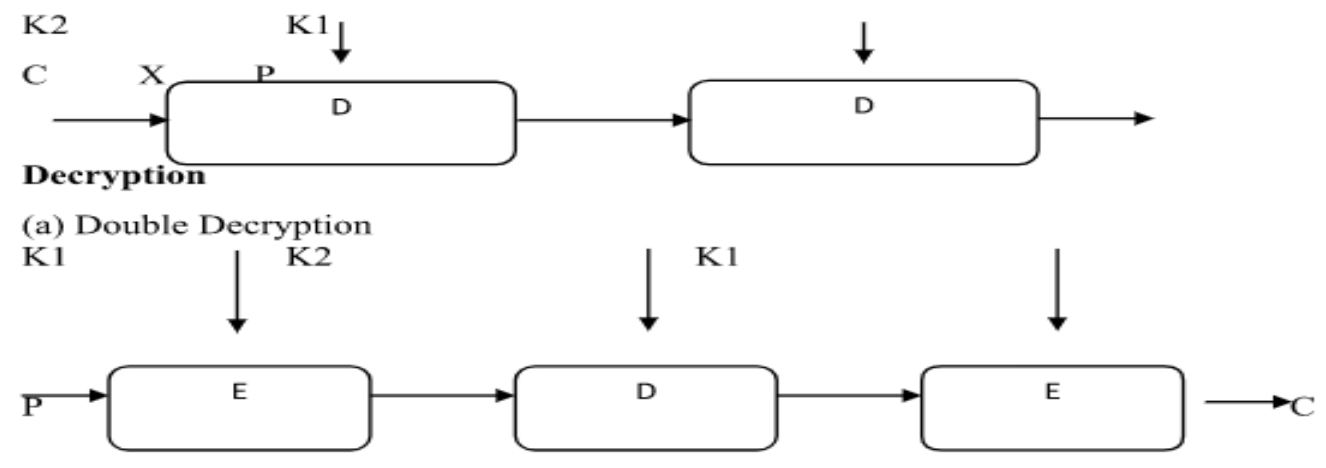

Encryption

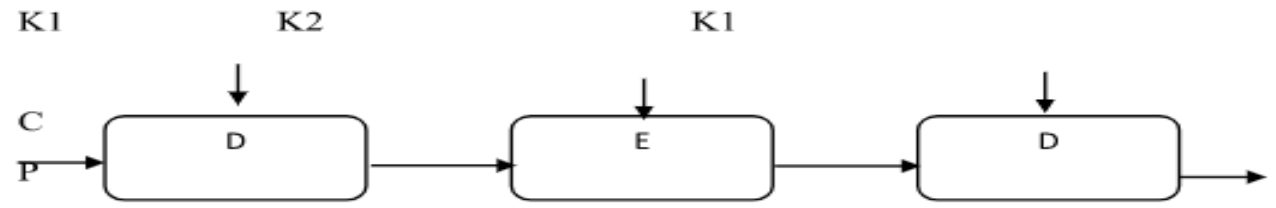




\section{Decryption}

(b) Triple Encryption

$$
\mathrm{C}=\mathrm{e}_{\mathrm{k} 2}\left(\mathrm{e}_{\mathrm{k} 1}(\mathrm{P})\right)
$$

Decryption requires that the keys be applied in reverse order:

$$
\mathrm{P}=\mathrm{d}_{\mathrm{k} 1}\left(\mathrm{~d}_{\mathrm{k} 2}(\mathrm{C})\right)
$$

For DES, this theme seemingly involves a key length of $56 \mathrm{x}$ a couple of $=112$ bits, transport concerning accomplice in Nursing emotional increment in technology high-quality.

it is shown that companion in Nursingy block secret writing cipher equal to Double DES is mot proof against an assault referred to as a meet-in-the-center attack, that was preliminary represented by using Diffie and dramatist in 1977.

An apparent counter to the meet-in-the-center assault is to make use of 3 stages of secret writing with 3 numerous keys. Be that due to the fact it can, it's the draw back of requiring a key duration of $56 \mathrm{x}$ three $=168$ bits, which will be to a degree awkward. As partner in Nursing choice, there was deliberate a triple mystery writing approach that utilizations without a doubt 2 keys. The functionality takes once accomplice in Nursing encryption-decryption-encryption (EDE) series, as shown inside the preceding parent:

$$
\mathrm{C}=\mathrm{e}_{\mathrm{k} 1}\left(\mathrm{~d}_{\mathrm{k} 2}\left(\mathrm{e}_{\mathrm{k} 1}(\mathrm{P})\right)\right)
$$

The advantage of the use of decryption for the second record stage is that it allows users of 3DES to decrypt data encrypted by using the older version of single DES:

$$
\mathrm{C}=\mathrm{e}_{\mathrm{k} 1}\left(\mathrm{~d}_{\mathrm{k} 1}\left(\mathrm{e}_{\mathrm{k} 1}(\mathrm{P})\right)\right)=\mathrm{e}_{\mathrm{k} 1}(\mathrm{P})
$$

Triple DES (or 3DES) with 2 keys could be a moderately documented alternative choice to DES and has been received to be used within the key administration pointers ANS X9.17 and ISO 8732 .

numerous scientists presently feel that 3-key triple DES is that the popular possibility. three-key 3DES has an green key length of 168 bits and is printed as follows:

$$
\mathrm{C}=\mathrm{e}_{\mathrm{k} 3}\left(\mathrm{~d}_{\mathrm{k} 2}\left(\mathrm{e}_{\mathrm{k} 1}(\mathrm{P})\right)\right)
$$

Backward compatibility with DES is provided by putting $\mathrm{K}_{3}=\mathrm{K}_{2}$ or $\mathrm{K}_{1}=\mathrm{K}_{2}$.

numerous internet-based applications have embraced 3-key 3DES, together with PGP (quite smart privateness) and S/MIME (secure/Multipurpose net Mail Extension).

\section{Existing system and PGP algorithm}

PGP is as well completely terrible at being clean, or utilize. The solid cryptography that PGP makes use of - open key cryptography is intelligent, however hard to wrap your head round. PGP bundle itself has been round when you consider that 1991, that makes it accomplice indistinguishable vintage from the primary forms of Microsoft home windows, and its appearance hasn't modified a whole lot of from that time ahead. the good news is that there ar several comes reachable currently which may additionally shroud the old installation of PGP and create it to a degree less complicated to utilize, substantially on the subject of cryptography and confirmatory email - the principle use of PGP. we have enclosed publications to putting in and operative this bundle some other place. before you play around with PGP or totally distinctive comes that utilization it, however, it merits price a few of mins information the requirements of open key encryption: what it's going to improve real you, what it can't do, and after you ought to make use of it.

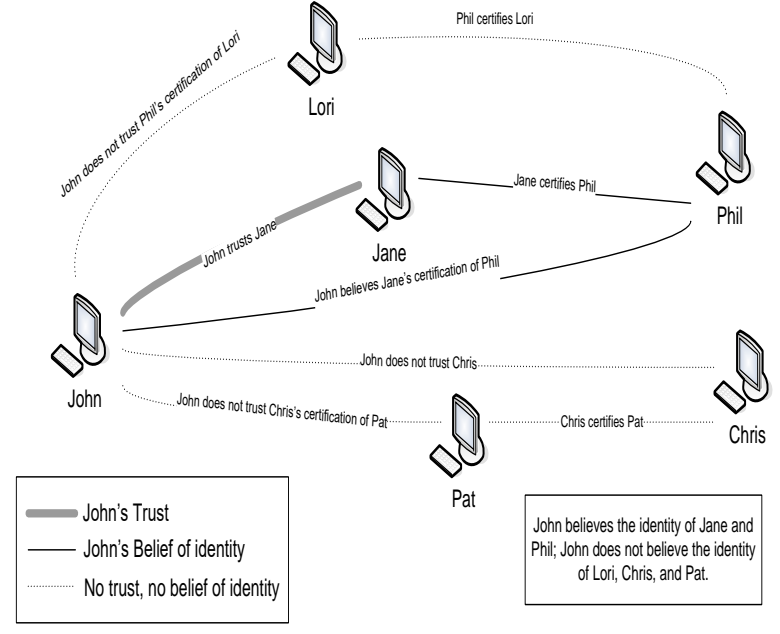

\section{Proposed system advanced blow fish algorithm}

\section{Blowfish}

blowfish is one in every of the fastest and filmable bilaterally symmetric key secret writing techniques, that turned into conferred in 1993 by means of countrywide institute of standards and generation customary, that has sixty 4 bit block size and has variable key lengths of thirty to 448 bits that surely adapts in hybrid cryptography [4-7]. in blowfish usually there vicinity unit fourteen rounds and key fashioned is occasionally a lot of powerful that is of path effective in opposition to brutal pressure assault. right here we generally tend to carry out each key and records extension and be a part of it [7]. throughout this way, this takes the advantage of of those 3 calculations that joins to border an prolonged key and gets useless in less time to relinquish better talent [3].

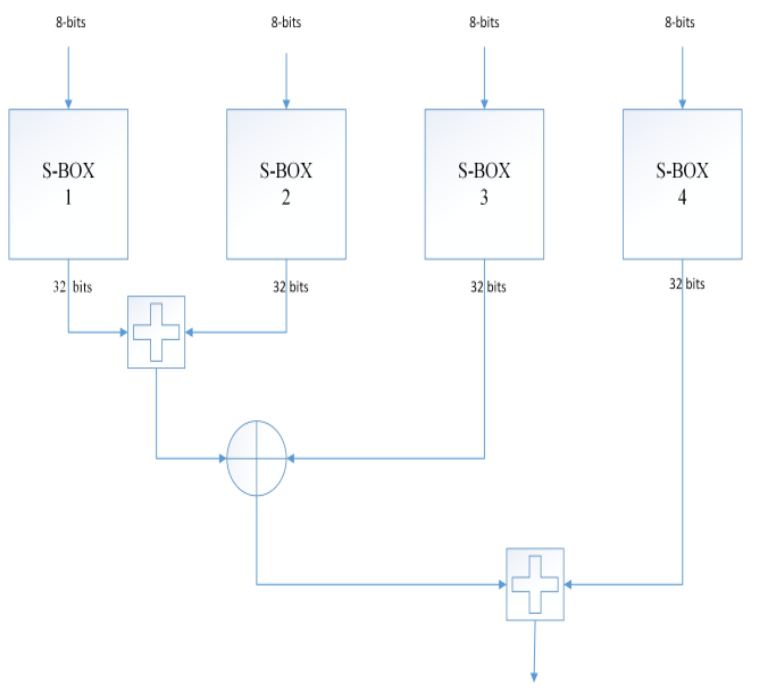

Fig. 2: key Expansion in Blowfish

As consistent with literature survey Blowfish algorithmic application performs faster than AES and DES algorithms. additionally AES calculation performs quicker than DES algorithmic application.

Performance $=$ Blowfish $>$ AES $>$ DES

Time taken for blowfish algorithm to complete the operation 
Time taken for AES algorithm to complete the operation $\mathrm{T}_{\mathrm{AES}}=\mathrm{x}_{2}+\alpha$

Time taken for DES algorithm to complete the operation $\mathrm{T}_{\mathrm{DES}}=\mathrm{x} 3+\beta$; where $\beta=\alpha+\mathrm{c}$

Generally total time taken

$\mathrm{T}_{\text {total }}=\mathrm{T}_{\mathrm{BF}}+\mathrm{T}_{\mathrm{AES}}+\mathrm{T}_{\mathrm{DES}}$

$\mathrm{T}_{\text {total }}=\mathrm{x}_{1}+\mathrm{x}_{2}+\mathrm{x}_{3}+\alpha+\beta$

Probability of Error in security:

In blowfish, Probability for $100 \%$ efficiency

$\mathrm{P}_{\mathrm{BF}}=1$

Least Probability of getting error

$\mathrm{P}_{\mathrm{BF}}=\mathrm{P}$

Total probability without error

$\mathrm{P}_{\mathrm{BF}(\mathrm{Total})}=(1-\mathrm{P})$

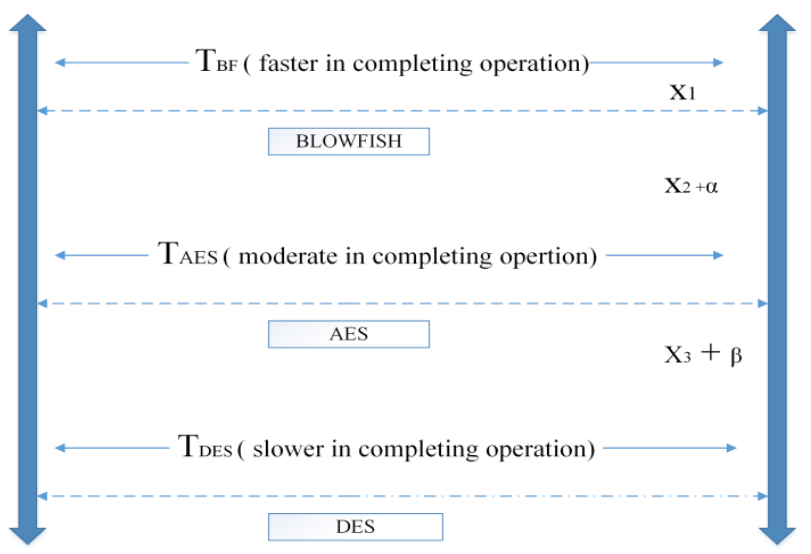

Fig. 3: Flow diagram showing time for completing operation Total time taken for Blowfish based on probability(fig3)
$T_{B F}=B * x_{1}\left[\frac{P_{B F(T o t a l)}}{100}\right]$

$T_{A E S}=B *\left[x_{2}+\alpha\right]\left[\frac{P_{A E S(T o t a l)}}{100}\right]$

For DES

$T_{D E S}=B *\left[x_{3}+\beta\right]\left[\frac{P_{D E S(\text { Total })}}{100}\right]$

Combining (1), (2), and (3)

$T_{\text {Totpro }}=T_{B F}+T_{A E S}+T_{D E S}$

$T_{\text {Totpro }}=B\left[\left[x_{1}\left[\frac{P_{B F(\text { Total })}}{100}\right]+\left[x_{2}+\alpha\right]\left[\frac{P_{A E S(\text { Total })}}{100}\right]+\left[x_{3}+\right.\right.\right.$ $\left.\left.\beta]\left[\frac{P_{D E S(\text { Total })}}{100}\right]\right]\right]$

1. About Algorithm Implementation

2. Diagram for Work Related and Comparison with Existing and Proposed Systems.

\section{Results}

\begin{tabular}{lllll}
\hline Input Size & Blowfish [Time In Sec] & PGP [Time In Sec] & AES [Time in Sec] \\
\hline 20,527 & 19 & 27 & 39 & DES [Time in Sec] \\
59,852 & 47 & 58 & 125 & 24 \\
158,959 & 158 & 257 & 324 & 74 \\
232,398 & 219 & 315 & 460 & 190 \\
& & & 276 \\
\hline
\end{tabular}

\section{Conclusion}

An cost-efficient rule must be pressured to provide maximum intense safety operation in much less time the aggregate mix of antecedently mentioned algorithms square degree additional secured and it likewise gives consummation in less time as once joined. we're able to likewise actualize some absolutely different algorithms to enhance the safety of the framework with the aid of enhancing the important thing length and what is greater by using utilising powerful aggregate of algorithms in future. The displayed recreation comes regarding incontestable that Blowfish incorporates a most famous execution over distinctive traditional mystery writing algorithms used. in view that Blowfish has no glorious security frail focuses up to this point, that makes it an exceptional contestant to be idea of as a commonplace mystery writing algorithms. AES incontestable poor execution comes regarding contrasted with absolutely unique algorithms because it needs all of the additional dealing with energy. utilizing CBC mode has enclosed greater managing time, however standard it honestly was fairly inapplicable significantly honestly utility that desires safer secret writing to a fairly expansive statistics squares 7 .

\section{References}

[1] Sowmya nag k., h.b.bhuvaneswari, nuthana.c, "Implementation of advanced encryption Standard-192 bit using multiple keys" ieeetranscation, vol 5,pg34-39,2012.

[2] Najib A. Kofahil "Performance evaluation of three Encryption/ decryption algoriithms" ISSN 0-7803-8294-3 IEEE,2014

[3] William Stallings "Cryptography and Network Security", Third Edition, Pearson Education Asia Publication, 2007

[4] Jawahar Thakur, Des, Aes And Blowfish: Symmetric Key Cryptography Algorithms Simulation Based Performance Analysis", International Journal of Emerging Technology and Advanced Engineering, ISSN 2250-2459, Volume 1, Issue 2 December 2011

[5] Dr. Mohammed M. Alani "DES96 - Improved DES Security", 7th International Multi-Conference on Systems, Signals and Devices, 2010

[6] Seung-johan "The improved data encryption standard (des) algorithm”leee transaction ISSN 0-7803-3567-8,volume ,issue ,December 1996.

[7] Michael C.-J. Lin "A VLSI Implementation of the Blowfish Encryption/Decryption Algorithm" National Science Council, R.O.C, NSC 88-2215-E-007-025. 
[8] Taiping Mo "Design of secure communications network system based on data encryption and digital signature" ISSN 978-161284-383-4,IEEE,2011.

[9] Daemen, J., and Rijmen, V. "Rijndael: The Advanced Encryption Standard.” D r. Dobb's Journal, March 2001, pp. 137-139

[10] Lei Zhang, Futai Zhang, "Certificateless Partially Blind Signatures," The 1st International Conference on Information Science and Engineering (ICISE), pp. 2883 - 2886, Dec 26-28, 2009.

[11] Penchalaiah, N. and Seshadri, R. "Effective Comparison and Evaluation of DES and Rijndael Algorithm (AES)", International Journal of Computer Science and Engineering, Vol. 02, No. 05, 2010, 1641-1645.

[12] Rivest, R. L., Shamir, A., Adelmann, L.: "A method for obtaining digital signature and public -key cryptosystems", Commun. ACM, 1978, VOL. 21, pp. 120-126

[13] Internet

Security Glossary", http://www.faqs.org/rfcs/rfc2828.html

[14] AamerNadeem et al, "A Performance Comparison of Data Encryption Algorithms", IEEE 2005

[15] Wireless Security Handbook,".Auerbach Publications 2005

[16] Performance Comparison: Security Design Choices," Microsoft Developer Network October 2002. http://msdn2.microsoft.com/en-us/library/ms978415.aspx

[17] Real 802.11 Security: Wi-Fi Protected Access and 802.11i ,". Addison Wesley 2003

[18] Block Cipher", http://en.wikipedia.org/wiki/Block_cipher

[19] Security In Wireless LANS And MANS ,". Artech House Publishers 2005

[20] DES Overview", [Explains how DES works in details, features and weaknesses]

[21] BRUCE SCHNEIER, "Applied Cryptography" , John Wiley \& Sons, Inc 1996

[22] Crypto++ benchmark", http://www.eskimo.com/ weidai/benchmarks.html [Results of comparing tens of encryption algorithms using different settings].

[23] Coder's Lagoon",http://www.hotpixel.net/software.html [List of resources to be used under GNU]

[24] T. Padmapriya and V.Saminadan, "Handoff Decision for Multiuser Multiclass Traffic in MIMO-LTE-A Networks", 2nd International Conference on Intelligent Computing, Communication \& Convergence (ICCC-2016) - Elsevier PROCEDIA OF COMPUTER SCIENCE, vol. 92, pp: 410-417, August 2016.

[25] S.V.Manikanthan and V.Rama“Optimal Performance Of Key Predistribution Protocol In Wireless Sensor Networks" International Innovative Research Journal of Engineering and Technology ,ISSN NO: 2456-1983,Vol-2,Issue -Special -March 2017.

[26] Rajesh, M., and J. M. Gnanasekar. \&quot;Constructing WellOrganized Wireless Sensor Networks with Low-Level Identification.\&quot; World Engineering \&amp; Applied Sciences Journal 7.1 (2016) 